\title{
The impact of fake news on social media and its influence on health during the COVID-19 pandemic: a systematic review
}

\author{
Yasmim Mendes Rocha ${ }^{1}$ - Gabriel Acácio de Moura ${ }^{2}$ - Gabriel Alves Desidério ${ }^{3}$ - Carlos Henrique de Oliveira ${ }^{3}$. \\ Francisco Dantas Lourenço ${ }^{3}$. Larissa Deadame de Figueiredo Nicolete ${ }^{3}$ (D)
}

Received: 15 June 2021 / Accepted: 20 September 2021

(C) The Author(s), under exclusive licence to Springer-Verlag GmbH Germany, part of Springer Nature 2021

\begin{abstract}
Purpose As the new coronavirus disease propagated around the world, the rapid spread of news caused uncertainty in the population. False news has taken over social media, becoming part of life for many people. Thus, this study aimed to evaluate, through a systematic review, the impact of social media on the dissemination of infodemic knowing and its impacts on health. Methods A systematic search was performed in the MedLine, Virtual Health Library (VHL), and Scielo databases from January 1, 2020, to May 11, 2021. Studies that addressed the impact of fake news on patients and healthcare professionals around the world were included. It was possible to methodologically assess the quality of the selected studies using the Loney and Newcastle-Ottawa Scales.

Results Fourteen studies were eligible for inclusion, consisting of six cross-sectional and eight descriptive observational studies. Through questionnaires, five studies included measures of anxiety or psychological distress caused by misinformation; another seven assessed feeling fear, uncertainty, and panic, in addition to attacks on health professionals and people of Asian origin. Conclusion By analyzing the phenomenon of fake news in health, it was possible to observe that infodemic knowledge can cause psychological disorders and panic, fear, depression, and fatigue.
\end{abstract}

Keywords Covid-19 $\cdot$ Fake news $\cdot$ Health $\cdot$ Infodemic knowing

This is a review article that has not been published before and is not being considered for publication anywhere. Authors confirm that the manuscript has been read and approved by all named authors and that no other person has met the authorship criteria, but it is not listed. We further confirm that none of us have any conflict of interest to declare. We would like to thank you for your attention and the opportunity given to submit our study, and agree, if the manuscript is accepted for publication, to the transfer of all copyright to the Journal of Public Health.

Larissa Deadame de Figueiredo Nicolete

larissanicolete@unilab.edu.br

1 Post-graduate Program in Pharmaceutical Sciences, Federal University of Ceará (UFC), Campus Porangabussu, Fortaleza, CE 60.430-370, Brazil

2 Post-graduate Program in Veterinary Sciences, State University of Ceará (UECE), Campus do Itaperi, Fortaleza, CE 60.714-903, Brazil

3 Health Sciences Institute, University of International Integration of the Afro-Brazilian Lusophony Brazil, CE 060 - Km51,

Redençao, CE 62785-000, Brazil

\section{Introduction}

Coronavirus 2019 disease (COVID-19), caused by the SARS$\mathrm{CoV}-2$ virus, led to the emergence of a pandemic, with a shift in economics, disruption in education, and various rules on home confinement (Munster et al. 2020). In this context of uncertainty, there was a need for new information about the virus, clinical manifestations, transmission, and prevention of the disease (Eysenbach 2020).

The rapid implementation of these measures, together with the number of significant deaths caused by the virus, ended up causing uncertainty in the population (Tangcharoensathien et al. 2020). In association with the generalized panic and the constant concern that COVID-19 caused, this culminated in the appearance of physical and psychological disorders, in addition to reduced immunity in the general population (Lima et al. 2020).

Previous studies indicate that the emergence of the pandemic and measures of social confinement caused the number of patients and health professionals with anxiety, sleep disorders and depression to increase; in addition, suicide rates were 
also considered high (Choi et al. 2020; Okechukwu et al. 2020). However, the use of social media and search queries to obtain information about the course of the disease is constantly expanding, and includes Twitter, Facebook and Instagram, Google Trends, Bing, Yahoo, and other more popular sources such as blogs, forums, or Wikipedia (Depoux et al. 2020).

Thus, information overload accompanied by fabricated and fraudulent news, also called fake news (FN), has emerged in the twentieth century to designate the fake news produced and published by mass communication vehicles such as social media, dominating traditional and social platforms, becoming increasingly part of many people's daily lives. FNs multiply rapidly and act as narratives that omit or add information to facts (Naeem et al. 2020).

The potential effect of FN stems from conspiracy theories, such as a biological weapon produced in China, water with lemon or coconut oil that could kill the virus, or drugs, which even if approved for other indications, could have potential effectiveness in prevention or treatment of COVID-19. Therefore, the impact of this massive dissemination of disease-related information is known as "infodemic knowledge" (Hua and Shaw 2020). Other worrisome examples of infodemic knowledge include cases of hydroxychloroquine overdose in Nigeria, drug shortages, changing treatment of patients with rheumatic and autoimmune diseases, and panic over supplies and fuel (CNN 2020; Tentolouris et al. 2021).

The World Health Organization (WHO 2020) has worked closely to track and respond to the most prevalent myths and rumors that can potentially harm public health. In this context, the objective of the study was to evaluate, through a systematic review, the impact of the media and the media during the pandemic caused by the new coronavirus, and to determine how the spread of infodemic impacts people's health.

\section{Methods}

This is a systematic literature review that aimed to use explicit and systematic methods to avoid the chance of risk of bias (Donato and Donato 2019). Therefore, the study followed a design according to the guidelines of Preferred Report items for Systematic Reviews (PROSPERO) and PRISMA Metaanalyses (PRISMA 2021) and the search procedures were filed in the database and registered in PROSPERO: CRD42021256508 (PROSPERO 2021).

\section{Searching strategy}

Search strategies were developed from the identification of relevant articles using the Medical Subjects Headings $(\mathrm{MeSH})$ in a combination of Boolean AND. The search by string and keyword was calculated as follows: "Covid-19" OR "SARS-CoV-2" AND "fake news" AND "health" OR "Covid-19" AND "fake news" OR "misinformation" AND "health". The strategy was performed using MedLine, Virtual Health Library (VHL), and Scielo databases. Search results were revised to prevent duplicate studies. The articles obtained were analyzed for relevance and step-by-step, as illustrated in Fig. 1. The report items for systematic review illustrate the PRISMA (PRISMA 2021) process used to report the results.

\section{Inclusion and exclusion criteria}

The search terms were oriented according to the Population, Intervention, Comparison, Results and Study Design (PICOS) approach, methodology used to select the studies included in the systematic search (Methley et al. 2014), as shown in Table 1. Cross-sectional studies, of cohorts or clinicians that addressed the impact of fake news on patients and health professionals around the world, were used. On the other hand, studies that did not refer to the proposed theme, review articles, or were letters and opinions were excluded. In addition, only full articles written in English, Portuguese (Brazil), and Spanish, published between January 1, 2020, and May 11, 2021, were reviewed.

\section{Assessment of risk of bias in included studies}

Internal quality was performed based on selected study designs using two scales to independently assess the risk of bias; Newcastle-Ottawa for cohort studies and Loney scale for cross-sectional studies. In case of disagreement between two researchers, the assessment was performed by a third experienced researcher (Santos et al. 2019). The assessment of the risk of bias between studies was assessed as shown in Tables 2 and 3 .

\section{Data extraction}

After collecting data from the articles, they were extracted and tabulated according to the information cited later:

1. Author.

2. Type of study.

3. Class FN.

4. Source of FNs.

5. Impact of FNs on health.

6. Age of participants.

7. Country of origin.

8. Number of patients.

9. Education. 


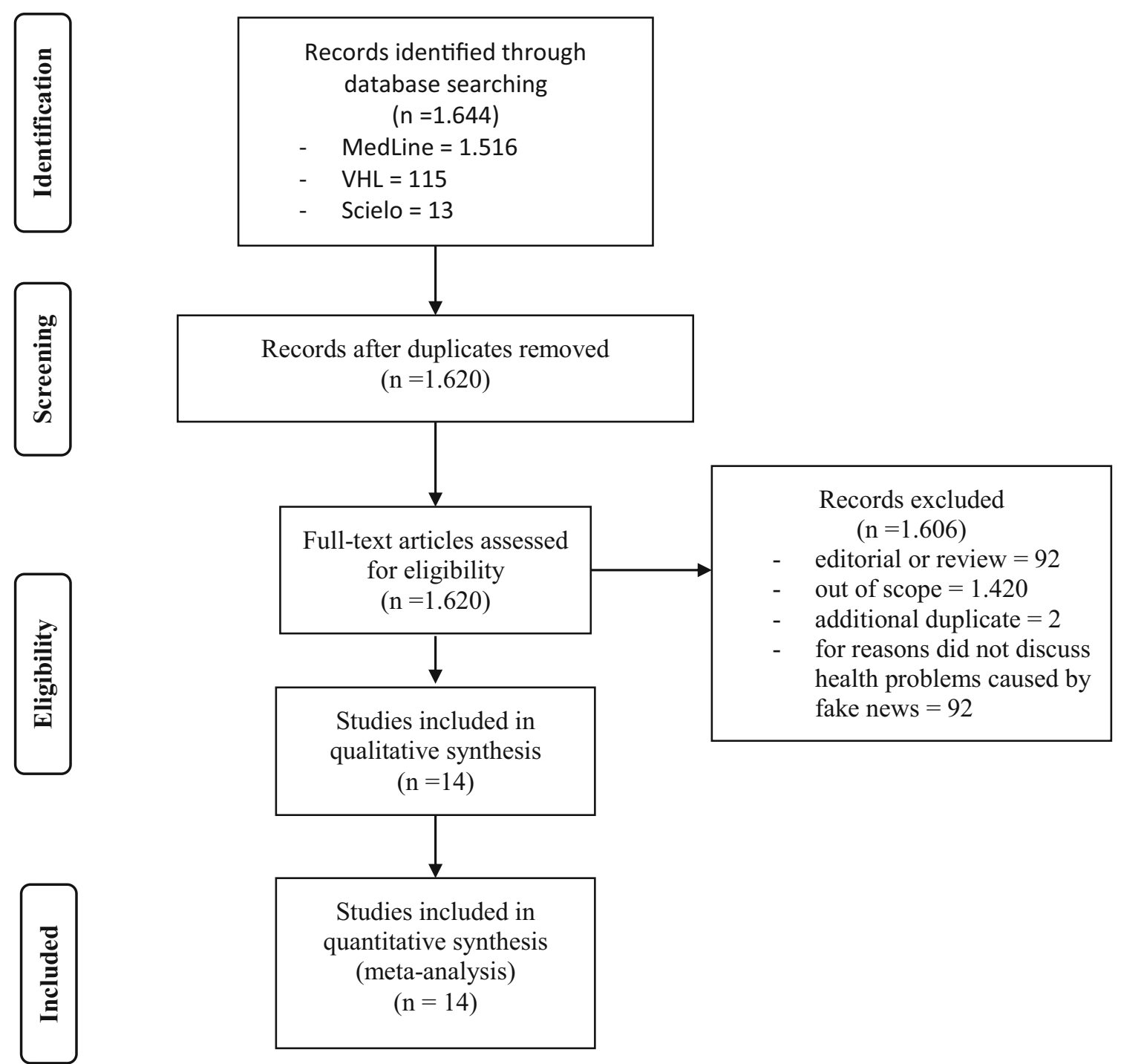

Fig. 1 Search strategy flowchart

\section{Results}

\section{Study selection}

The search strategy identified 1644 publications through the MedLine database, the Virtual Health Library (VHL), and Scielo databases. Of these studies found, 24 were removed for being duplicative and 1606 for being within the exclusion criteria. Based on this, 14 studies met the inclusion criteria and were suitable to be considered in the present review, as shown in Fig. 1.
Table 1 Approach to study selection (PICO) following systematic search

\begin{tabular}{|c|c|c|}
\hline Description & Abbreviation & Question components \\
\hline Population & $\mathrm{P}$ & $\begin{array}{l}\text { Lay population or health professionals, population with different levels of } \\
\text { education and in different countries }\end{array}$ \\
\hline Intervention & I & Use of an online questionnaire to analyze the impacts of FNs on health \\
\hline Comparison & $\mathrm{C}$ & Not applied \\
\hline Outcomes & $\mathrm{O}$ & Social media platforms contribute to the spread of FN \\
\hline $\begin{array}{l}\text { Type of } \\
\text { study }\end{array}$ & $\mathrm{S}$ & Clinical trials; cohort studies; cross-sectional studies \\
\hline
\end{tabular}

Database searched in May 2021 
Table 2 Methodological quality of cross-sectional studies (Loney Scale)

\begin{tabular}{lllllllllll}
\hline References & \multicolumn{3}{l}{$\begin{array}{l}\text { Are the study methods } \\
\text { valid? }\end{array}$} & & & & & $\begin{array}{l}\text { What is the interpretation } \\
\text { of the results? }\end{array}$ & $\begin{array}{l}\text { How likely are } \\
\text { the results? }\end{array}$ & Final score \\
\cline { 2 - 6 } Criteria & 1 & 2 & 3 & 4 & 5 & 6 & 7 & 8 & 8 \\
\hline Ruíz-Frutos et al. & 1 & 1 & 1 & 1 & 1 & 1 & 1 & 1 & 7 \\
Najmul-Islam et al. & 1 & 1 & 1 & 1 & 1 & 1 & 0 & 1 & 6 \\
Talwar et al. & 0 & 1 & 1 & 1 & 1 & 1 & 0 & 1 & 8 \\
Sallam et al. & 1 & 1 & 1 & 1 & 1 & 1 & 1 & 1 & 8 \\
Duplaga & 1 & 1 & 1 & 1 & 1 & 1 & 1 & 1 & 6 \\
Secosan et al. & 1 & 1 & 0 & 1 & 1 & 1 & 0 & 1 & 6 \\
\hline
\end{tabular}

Questions in header relate to different criteria of quality as measured by the Loney Scale:

1 - Is the study design and sampling appropriate to answer the research question? 2 - Is the sample base adequate? 3 - Is the sample size adequate? 4 - Are adequate and standardized objective criteria used to measure motor development? 5 - Was EDM applied in an unbiased way? 6 - Is the response rate adequate? 7 - Were the EDM results presented in a detailed way? 8 - Are participants and context described in detail and can they be generalized to other situations?

Numbers alongside each reference relate to quality of response questions above: 1 = adequate, $2=$ inadequate

\section{Study characteristics}

Of all the studies included, six were cross-sectional (RuizFrutos et al. 2020; Islam et al. 2020; Talwar et al. 2020; Sallam et al. 2020; Duplaga 2020; Secosan et al. 2020) and eight were descriptive observational studies (Radwan et al. 2020; Sun et al. 2020; Ahmad and Murad 2020; Almomani and Al-Qur'an 2020; Roozenbeek et al. 2020; Montesi 2020; Schmidt et al. 2020; Fernández-Torres et al. 2021). The sample size of the fourteen selected articles was a total of 571,729 participants, 1467 false new items, and 2508 reports. Most participants were over 18 years of age. The studies were conducted in 14 different countries, including Palestine $(n=1)$,
Spain $(n=4), \operatorname{India}(n=1), \operatorname{Bangladesh}(n=1), \operatorname{Iraq}(n=1)$, Mexico $(n=1)$, United States of America $(n=1)$, United Kingdom $(n=1)$, Ireland $(n=1)$, Jordan $(n=2)$, China $n=$ $1)$, South Africa $(n=1)$, Poland $(n=1)$ and Romania $(n=$ 1 ), each study being able to evaluate more than one country. Other characteristics of the study and the results of the primary study are summarized in Table 4.

\section{The potential risks of misinformation}

The results included varied in our review. It was possible to identify that misinformation could trigger varied disturbances to an individual's perception of FNs. In five papers, the

Table 3 Methodological quality on the Newcastle-Ottawa Scale (NOS)

\begin{tabular}{|c|c|c|c|c|c|c|c|c|c|}
\hline \multirow{2}{*}{$\begin{array}{l}\text { Study } \\
\text { Criteria }\end{array}$} & \multicolumn{9}{|c|}{ NOS-items scores } \\
\hline & $\begin{array}{l}\text { Selection } \\
1\end{array}$ & $\begin{array}{l}\text { Selection } \\
2\end{array}$ & $\begin{array}{l}\text { Selection } \\
3\end{array}$ & $\begin{array}{l}\text { Selection } \\
4\end{array}$ & $\begin{array}{l}\text { Comparability } \\
\text { la }\end{array}$ & $\begin{array}{l}\text { Results } \\
1\end{array}$ & $\begin{array}{l}\text { Results } \\
2\end{array}$ & $\begin{array}{l}\text { Results } \\
3\end{array}$ & Final score \\
\hline Radwan et al. & 1 & 1 & 1 & 1 & 0 & 1 & 1 & 1 & 7 \\
\hline Sun et al. & 1 & 1 & 1 & 1 & 0 & 1 & 1 & 1 & 7 \\
\hline Ahmad et al. & 1 & 1 & 0 & 1 & 0 & 1 & 1 & 1 & 6 \\
\hline Almomani & 1 & 1 & 1 & 1 & 0 & 1 & 1 & 1 & 7 \\
\hline Roozenbeek et al. & 1 & 1 & 1 & 1 & 0 & 1 & 1 & 1 & 7 \\
\hline Montesi & 1 & 1 & 1 & 1 & 0 & 1 & 1 & 0 & 6 \\
\hline Schmidt et al. & 1 & 1 & 1 & 1 & 0 & 1 & 1 & 1 & 7 \\
\hline Fernandéz-Torres et al. & 1 & 1 & 1 & 1 & 0 & 1 & 1 & 1 & 7 \\
\hline
\end{tabular}

Questions in header relate to different criteria of quality as measured by the NOS:

Selection 1: representativeness of the exposed cohort; Selection 2: selection of the unexposed cohort; Selection 3: exposure determination; Selection 4: demonstration that the result of interest was not present at baseline; Comparability 1a and 1b: comparability of cohorts based on design or analysis; Results 1: result evaluation; Results 2: follow-up of cohorts; Results 3: adequacy of cohort follow-up 


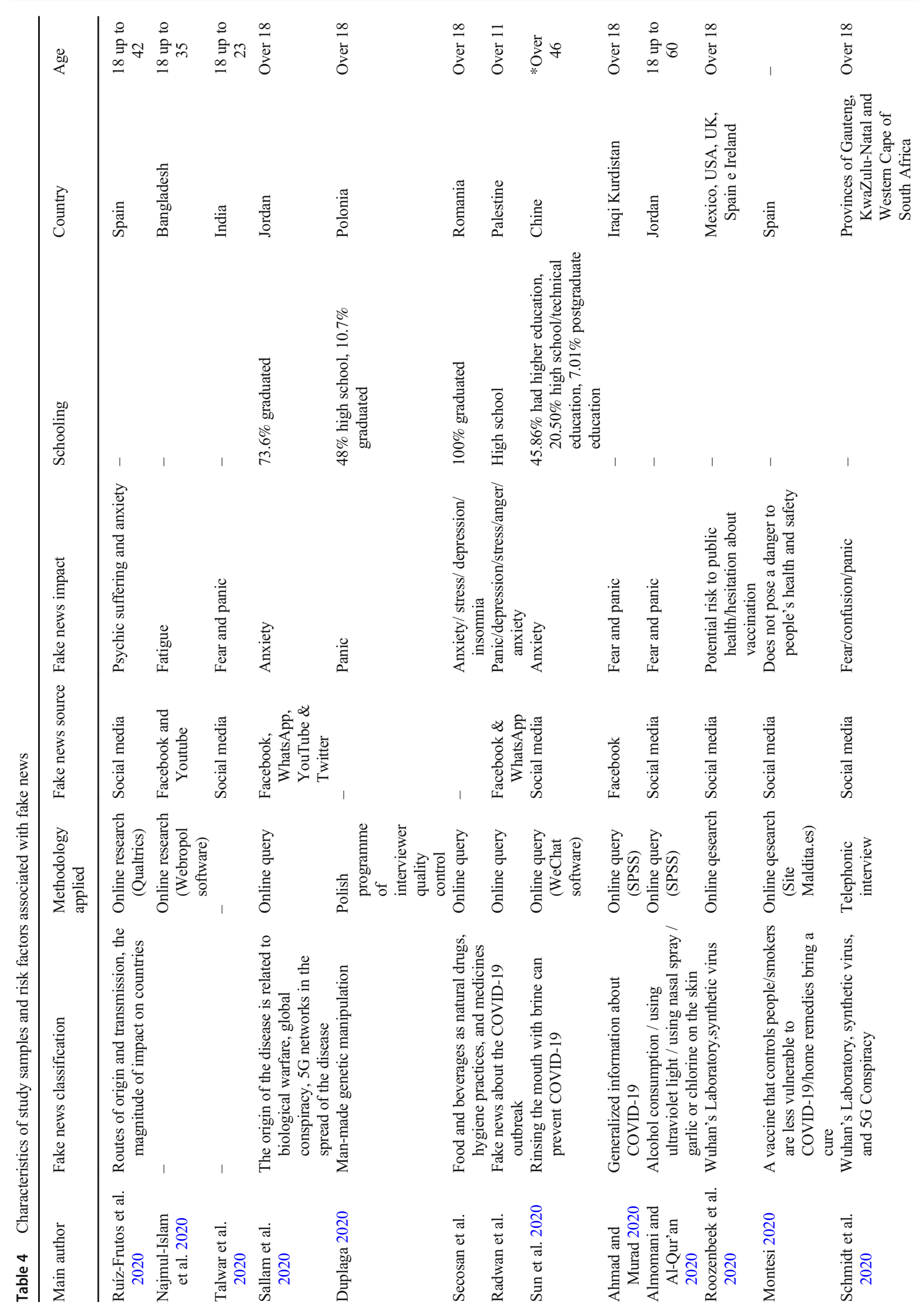


population was observed to be more prone to fearful situations (Talwar et al. 2020; Ahmad and Murad 2020; Almomani and Al-Qur'an 2020; Schmidt et al. 2020; Fernández-Torres et al. 2021). Consequently, two studies found that a proportion of these patients who reported being afraid because of the influence of FNs reported being confused as to the veracity of this transmitted information (Schmidt et al. 2020; FernándezTorres et al. 2021). Our review also found that this situation of fear and confusion can lead to the onset of panic (Talwar et al. 2020; Radwan et al. 2020; Duplaga 2020; Ahmad and Murad 2020; Almomani and Al-Qur'an 2020; Schmidt et al. 2020). In which, the set between the perceptual aspects to these FN can lead to milder symptoms such as fatigue (Islam et al. 2020), stress (Secosan et al. 2020; Radwan et al. 2020), insomnia (Secosan et al. 2020), and anger (Radwan et al. 2020). The literature also informs us that in addition to milder symptoms inherent to a state of confusion with regard to perceived misinformation conveyed, there is a likelihood of more complex symptomatologies as was reported in five studies with an increase in the number of patients with anxiety (Ruiz-Frutos et al. 2020; Sallam et al. 2020; Secosan et al. 2020; Radwan et al. 2020; Sun et al. 2020). Patients have also reported being affected by depression processes inherent to these FNs (Secosan et al. 2020; Radwan et al. 2020).

\section{Susceptibility to spreading fake news according to education and age of the population}

To understand the behavior of rumor spreading among the population, our findings reveal that the age of the patients who participated in the study varied mainly between 18 and 60 years, which could infer that a good portion of individuals in different age groups could be susceptible to FN spread through social media. However, in a single study, it was found that people over the age of 76 were more susceptible to being influenced by fake news as well as spreading this information (Sun et al. 2020). Another important finding in the literature indicates that susceptibility to interacting with FN is independent of the individual educational level of each study subject, where in four studies it was observed that the patients involved were in secondary school (Duplaga 2020; Radwan et al. 2020; Sun et al. 2020), five studies addressed the susceptibility of undergraduate patients to FN (Sallam et al. 2020; Duplaga 2020; Secosan et al. 2020; Sun et al. 2020; FernándezTorres et al. 2021), and in two studies graduate patients were observed (Sun et al. 2020; Fernández-Torres et al. 2021).

\section{Content and propagation of fake news circulating on social networking platforms}

It was possible to verify in the selected articles that the social network Facebook had the greatest participation in the selected studies (Islam et al. 2020; Sallam et al. 2020; Fernández- 
Torres et al. 2021), followed by Youtube in three studies (Islam et al. 2020; Sallam et al. 2020; Fernández-Torres et al. 2021) and WhatsApp in three more studies (Sallam et al. 2020; Radwan et al. 2020; Fernández-Torres et al. 2021); Twitter appeared in only one study (Sallam et al. 2020). Among the main FNs, we had the disclosure that the consumption of food, vitamins, and beverages improved the clinical condition of the affected patient, in addition to reducing the contamination rate (Islam et al. 2020; Secosan et al. 2020). In other studies, the infection improved with the use of mouthwashes and cutaneous substances (Sun et al. 2020; Almomani and Al-Qur'an 2020). News related to viral spread, such as the creation of the virus in the laboratory and the spread of the virus by vectors such as mosquitoes, were also addressed (Ahmad and Murad 2020; Roozenbeek et al. 2020; Montesi 2020). Vaccines have also become targets of fake news in studies (Montesi 2020).

\section{Discussion}

In the context of the pandemic, the media emerged to seek information about the disease. However, many occurrences were false news masquerading as reliable disease prevention and control strategies, which created an overload of misinformation. In this process, there was interference in the behavior and health of people, generating social unrest associated with violence, distrust, social disturbances, and attacks on health professionals (Moscadelli et al. 2020; Apuke and Omar 2021).

Overall, our review suggests that people of different nationalities were affected by sharing unverified information. In all the studies included, totaling 1467 news and 2508 reports, the results show that people trust the information they find on social networks, and through these accounts ended up believing and being affected by this information. Only one author pointed out that the news did not represent a danger to people's health and safety, being considered harmless. This fact was explained by Aleinikov et al. (2020) pointing out that in this delicate process, the important thing is to relate the perception of risk found in social media and trust in the information provided by institutions (Aleinikov et al. 2020).

These tools, while becoming increasingly popular, are also increasingly exposed to unreliable information. As a result, people feel anxious, depressed, or emotionally exhausted, and these expressive health effects are directly associated with the spread of this information (Lin et al. 2020). So much so, that when analyzing our data, it was realized that this interaction can come with both mild effects and more serious psychological problems. This is also consistent with the literature, according to Jiang (2021), who evaluated the possible psychological impact of social media on students during the pandemic and found an increase in the anxiety levels of these students, as well as a worsening in academic performance and physical exhaustion (Jiang 2021).

The proliferation of false news has consequences for public health because it fuels panic among people and discredits the scientific community in the eyes of public opinion. For example, a popular myth that consumption of pure alcohol — methanol - could eliminate the virus in the contaminated body killed approximately 800 people in Iran, while another 5876 people were hospitalized for methanol poisoning (HassanianMoghaddam et al. 2020). As demonstrated in our evaluation, Almomani and Al-Qur'an 2020 and Secosan et al. 2020, in their reports also claim that the participants, in fact, believed that alcohol consumption cured COVID-19 (Secosan et al. 2020; Almomani and Al-Qur'an 2020).

Based on the literature, even social media that play a significant role in disseminating true news about COVID-19 have also been linked to illness, because as platforms that help to spread public health messages to people, they also promote opinionated reporting. and concerns about the disease (Galea et al. 2020). In fact, the results pointed out in this review reveal that $36 \%$ of the authors showed that exposure to infodemic knowledge generated fear, panic, depression, stress, and anxiety in people interviewed through an online questionnaire. This is corroborated by a cross-sectional study carried out by Olagoke et al. (2020), that when evaluating 501 participants, the anxiety and depression score was related to news exposure in the traditional media, showing a prevalence of depressive symptoms and a greater perceived vulnerability, causing great psychological impact.

Our results indicate that different age groups have susceptibility to interact with the FN propagated by social media, especially in the elderly population. These results were also verified in a previous study by Guimarães et al. 2021, who aimed to assess the population's knowledge about COVID-19 and misinformation from an anonymous online survey and, with this, some parameters such as gender, education, and age were shown to be directly associated with a better perception of health issues in the context of the pandemic (Guimarães et al. 2021). The same was also seen by Hayat et al. 2020, who explored the public's understanding of the current situation of the COVID-19 from online forms and concluded that participants with ages ranging from 16 to 29 years obtained better scores than older participants (Hayat et al. 2020). Such a fact is associated with the digital media literacy of individuals primarily over the age of 60 who end up not reliably determining the trustworthiness of online news, thus needing to develop literacy competencies that encompass the types of skills needed to identify questionable content (Guess et al. 2019).

To understand the behavior of spreading rumors among the elderly population, our results show that most respondents $(74.82 \%)$ negatively evaluated the dissemination of fake news, while $2.52 \%$ did not care anyway. Among them, the 
correlation between the spread of rumors and anxiety was negatively associated, as they influence the behavior and perception of the elderly to understand what a fact is and what is fake news. Research shows that individuals over 65 years share up to seven times more unverified information when compared to other age groups, often in order to feel useful, active, and connected (Guess et al. 2019). Certainly, psychological interventions are mainly recommended to vulnerable populations and health professionals (Van Der Linden et al. 2020).

Our results also showed that $36 \%$ of the authors reported that, regardless of age, it was possible for participants to experience fatigue, anguish, and psychological distress, in addition to having a higher probability of developing anxietyrelated symptoms. This is contradicted in two previous studies by Huang and Zhao (2020) and Wang et al. (2020); when evaluating the psychological impact of the uncontrolled spread of COVID-19, they realized that the manifestations of anxiety and psychological outbreaks were more common especially in the younger population who used social networks for a longer time (Huang and Zhao 2020; Wang et al. 2020). On the other hand, pandemic uncertainty and confinement created considerable levels of stress in young people, especially women, in Switzerland (Mohler-Kuo et al. 2021). It was further shown that misinformation fueled by rumors and conspiracy theories led to physical harassment and violent attacks against healthcare professionals and people of Asian origin in $28 \%$ of the results shown in this review. This finding is in line with a study that shows that conspiracy theories are not a new phenomenon, but they increase in times of crisis. Thus, people who believe in this "conspiracy world" are less likely to comply with social norms (Imhoff and Lamberty 2020).

The impact of denial and its association with fake news presents itself as a social phenomenon through the production of controversial theses to the scientific consensus (Duarte and César 2020). Good examples of denial content can be the emergence of the earthmoving movement, the global warming farce, and anti-vaccination discourses (Vasconcelos-Silva and Castiel 2020). With regard to the COVID-19 pandemic, denialism takes on an expression never seen before, in which the number of people who spread this news grows more and more, and therefore results in an increase in the number of deaths of the most vulnerable patients (Morel 2021).

Importantly, false information has been a genuine concern among social-media platforms and governments, which have implemented strategies to contain misinformation and fake news during the pandemic. Of the social-media platforms, in order to contain the advance of FNs, Facebook has implemented a new feature to inform users when they engage with unverified information (BBC 2020). Another way to counteract misinformation is to seek support and discuss actions that authorities or public agencies could take to mitigate the spread of conspiracy theories, and encourage users to flag inappropriate content to social-media companies (González-Padilla and Tortolero-Blanco 2020).

\section{Conclusion}

Social-media platforms have contributed to the spread of false news and conspiracy theories during the new coronavirus pandemic. When analyzing the phenomenon of fake news in health, it is possible to observe that infodemic knowledge is part of people's lives around the world, causing distrust in Governments, researchers, and health professionals, which can directly impact people's lives and health. When analyzing the potential risks of misinformation, panic, depression, fear, fatigue, and the risk of infection influence psychological distress and emotional overload. In the COVID-19 pandemic, the disposition to spread incorrect information or rumors is directly related to the development of anxiety in populations of different ages.

Acknowledgments The authors would like to thank the CAPES and FUNCAP for the fellowships of Yasmim M Rocha and Gabriel A de Moura.

Author contributions Yasmim Mendes Rocha: bibliographic research, concepts, methodology, writing, and data analysis. Gabriel Acácio de Moura: bibliographic research, methodology, revision, editing, and data analysis. Gabriel Alves Desidério: reading of included articles and review. Carlos Henrique de Oliveira: translation into English, reading of articles, and writing. Francisco Dantas Lourenço: article reading and review. Larissa Deadame de Figueiredo Nicolete: article idea, supervision, methodology, research, formal analysis, and editing.

Funding This study was supported by the Coordination for the Improvement of Higher Education Personnel (CAPES) and the Cearense Foundation for Scientific and Technological Development Support (FUNCAP).

\section{Declarations}

Conflict of interest The authors declare no conflict of interest.

\section{References}

Ahmad AR, Murad HR (2020) The impact of social media on panic during the COVID-19 pandemic in Iraqi Kurdistan: online questionnaire study. J Medical Internet Res 22:e19556. https://doi.org/10. 2196/19556

Aleinikov AV, Maltseva DA, Sunami AN (2020) Information management of the risks and threats of the Covid-19 pandemic. Sci Tech Inf Process 47:200-206. https://doi.org/10.3103/S0147688220030090

Almomani H, Al-Qur'an W (2020) The extent of people's response to rumors and false news in light of the crisis of the Corona virus. Ann Med Psychol 178(7):684-689. https://doi.org/10.1016/j.amp.2020. 06.011 
Apuke OD, Omar B (2021) Fake news and COVID-19: modelling the predictors of fake news sharing among social media users. Telemat Inform 56:101475. https://doi.org/10.1016/j.tele.2020.101475

BBC News (2020) Coronavirus: Facebook alters virus action after damning misinformation report (Joe Tidy, cyber-security reporter). https://www.bbc.com/news/technology-52309094

Choi EPH, Hui BPH, Wan EYF (2020) Depression and anxiety in Hong Kong during COVID-19. Int J Environ Res Public Health 17:37403750. https://doi.org/10.3390/ijerph17103740

CNN (2020) Nigeria records chloroquine poisoning after Trump endorses it for coronavirus treatment. Busari S, Adebayo B. CNN International, 23 March 2020. Available in: https://edition.cnn. com/2020/03/23/africa/chloroquine-trump-nigeria-intl/index.htm. February 21, 2021, date of last access

Depoux A, Martin S, Karafillakis E, Preet R, Wilder-Smith A, Larson H (2020) The pandemic of social media panic travels faster than the COVID-19 outbreak. J Travel Med 27(3):taaa031. https://doi.org/ $10.1093 / \mathrm{jtm} / \mathrm{taaa} 031$

Donato H, Donato M (2019) Stages for undertaking a systematic review. Acta Med Port 32: 227-235. https://doi.org/10.20344/amp.11923

Duarte AM, César MRA (2020) Negação da política do negacionismo como política: Pandemia e democracia. Educ Realid 45:e109146. https://doi.org/10.1590/2175-6236109146

Duplaga M (2020) The determinants of conspiracy beliefs related to the COVID-19 pandemic in a nationally representative sample of internet users. Int J Environ Res Public Health 17:7818. https://doi.org/ 10.3390/ijerph17217818

Eysenbach G (2020) How to fight an infodemic: the four pillars of infodemic management. J Med Internet Res 22:e21820. https://doi. org $/ 10.2196 / 21820$

Fernández-Torres MJ, Almansa-Martínez A, Chamizo-Sánchez R (2021) Infodemic and fake news in Spain during the COVID-19 pandemic. Int J Env Res Public Health 18:1781. https://doi.org/10.3390/ ijerph18041781

Galea S, Merchant RM, Lurie N (2020) The mental health consequences of COVID-19 and physical distancing: the need for prevention and early intervention. JAMA Intern Med 180:817-818. https://doi.org/ 10.1001/jamainternmed.2020.1562

González-Padilla DA, Tortolero-Blanco L (2020) Social media influence in the COVID-19 pandemic. Int Braz J Urol 46:120-124. https://doi. org/10.1590/S1677-5538.IBJU.2020.S121

Guess A, Nagler J, Tucker J (2019) Less than you think: prevalence and predictors of fake news dissemination on Facebook. Sci Adv 5: eaau4586. https://doi.org/10.1126/sciadv.aau4586

Guimarães V, Leandro M, Cassiano C, Marques A, Motta C, Silva A, Sousa M, Silveira L, Pardi T, Gazotto F, Silva M, Rodrigue V Jr, Rodrigues W, Oliveira C (2021) Knowledge about COVID-19 in Brazil: cross-sectional web-based study. JMIR Public Health Surveill 7:e24756. https://doi.org/10.2196/24756

Hassanian-Moghaddam H, Zamani N, Kolahi A-A, McDonald R, Hovda KE (2020) Double trouble: methanol outbreak in the wake of the COVID-19 pandemic in Iran - a cross-sectional assessment. Crit Care 24:1-3. https://doi.org/10.1186/s13054-020-03140-w

Hayat K, Rosenthal M, Xu S, Arshad M, Li P, Zhai P, Desalegn G, Fang $Y$ (2020) View of Pakistani residents toward coronavirus disease (COVID-19) during a rapid outbreak: a rapid online survey. Int J Environ Res Public Health 17:3347. https://doi.org/10.3390/ ijerph17103347

Hua J, Shaw R (2020) Corona virus (Covid-19)“infodemic" and emerging issues through a data lens: the case of China. Int J Env Res Public Health 17:2309. https://doi.org/10.3390/ijerph17072309

Huang Y, Zhao N (2020) Generalized anxiety disorder, depressive symptoms and sleep quality during COVID-19 outbreak in China: a webbased cross-sectional survey. Psychiatry Res 288:112954. https:// doi.org/10.1016/j.psychres.2020.112954
Imhoff R, Lamberty P (2020) A bioweapon or a hoax? The link between distinct conspiracy beliefs about the coronavirus disease (COVID19) outbreak and pandemic behavior. Soc Psychol Personal Sci 11: 1110-1118. https://doi.org/10.1177/1948550620934692

Islam AKMN, Laato S, Talukder S, Sutinen E (2020) Misinformation sharing and social media fatigue during COVID-19: an affordance and cognitive load perspective. Technol Forecast Soc Chang 159: 120201. https://doi.org/10.1016/j.techfore.2020.120201

Jiang Y (2021) Problematic social media usage and anxiety among university students during the COVID-19 pandemic: the mediating role of psychological capital and the moderating role of academic burnout. Front Psicol 12:76-88. https://doi.org/10.3389/fpsyg.2021. 612007

Lima SO, Da Silva MA, Santos MLD, De Jesus CVF (2020) Reflexão sobre o estado físico e mental dos profissionais de saúde em época de Covid-19. Interfaces Científicas-Saúde e Ambiente 8:142-151. https://doi.org/10.17564/2316-3798.2020v8n2p142-151

Lin Y, Hu Z, Alias H, Wong LP (2020) Influence of mass and social media on psychobehavioral responses among medical students during the downward trend of COVID-19 in Fujian, China: crosssectional study. J Med Internet Res 22(7):e19982. https://doi.org/ $10.2196 / 19982$

Methley AM, Campbell S, Chew-Graham C, McNally R, Cheraghi-Sohi S (2014) PICO, PICOS and SPIDER: a comparison study of specificity and sensitivity in three search tools for qualitative. BMC Health Serv Res 14:579. https://doi.org/10.1186/s12913-014-05790

Mohler-Kuo M, Dzemaili S, Foster S, Werlen L, Walitza S (2021) Stress and mental health among children/adolescents, their parents, and young adults during the first COVID-19 lockdown in Switzerland. Int J Env Res Public Health 18:4668. https://doi.org/10.3390/ ijerph18094668

Montesi M (2020) Understanding fake news during the Covid-19 health crisis from the perspective of information behaviour: the case of Spain. J Librariansh Inform Science 2020:0961000620949653. https://doi.org/10.1177/0961000620949653

Morel A (2021) Negacionismo da Covid-19 e educação popular em saúde: para além da necropolítica. Trab Educ Saúde 19. https://doi. org/10.1590/1981-7746-sol00315

Moscadelli A, Albora G, Biamonte MA et al (2020) Fake news and Covid-19 in Italy: results of a quantitative observational study. Int J Env Res Public Health 17:5850. https://doi.org/10.3390/ ijerph17165850

Munster VJ, Koopmans M, Doremalen NV, Riel DV, Wit E (2020) A novel coronavirus emerging in China-key questions for impact assessment. N Engl J Med 382:692-694. https://doi.org/10.1056/ NEJMp2000929

Naeem SB, Bhatti R, Khan A (2020) An exploration of how fake news is taking over social media and putting public health at risk. Health Inf Libr J 38(2):143-149. https://doi.org/10.1111/hir.12320

Okechukwu EC, Tibaldi L, Torre GL (2020) The impact of COVID-19 pandemic on mental health of nurses. Clin Ter 171 (5):e399-e400. https://doi.org/10.7417/CT.2020.2247

Olagoke AA, Olagoke OO, Hughes AM (2020) Exposure to coronavirus news on mainstream media: the role of risk perceptions and depression. Br J Health Psychol 25:865-874. https://doi.org/10.1111/bjhp. 12427

PRISMA (2021) Prisma Statement. http://www.prisma-statement.org/ PRISMAStatement. Access in: May 11,2021. systematic reviews. BMC Health Serv Res 14(1):1-10

PROSPERO (2021) International prospective register of systematic reviews. University of York, York, UK. https://www.crd.york.ac.uk/ prospero/. Access 11 March 202

Radwan E, Radwan A, Radwan W (2020) The role of social media in spreading panic among primary and secondary school students during the COVID-19 pandemic: an online questionnaire study from 
the Gaza Strip, Palestine. Heliyon 6:e05807. https://doi.org/10. 1016/j.heliyon.2020.e05807

Roozenbeek J, Schneider CR, Dryhurst S et al (2020) Susceptibility to misinformation about COVID-19 around the world. Royal Soc Open Sci 7:201199. https://doi.org/10.1098/rsos.201199

Ruiz-Frutos C, Ortega-Moreno M, Dias A, Bernardes JM, García-Iglesias JJ, Gómez-Salgado J (2020) Information on COVID-19 and psychological distress in a sample of non-health workers during the pandemic period. Int J Env Res Public Health 17:6982. https://doi. org/10.3390/ijerph17196982

Sallam M, Dababseh D, Yaseen A et al (2020) COVID-19 misinformation: Mere harmless delusions or much more? A knowledge and attitude cross-sectional study among the general public residing in Jordan. PLoS One 15(12):e0243264. https://doi.org/10.1371/ journal.pone. 0243264

Santos MCS, Shimano SGN, Araújo LGO, Pereira K (2019) Application of Motor Development Scale: an integrative review. Revista CEFAC 21(4):1516-1846. https://doi.org/10.1590/1982-0216/ 20192149918

Schmidt T, Cloete A, Davids A, Makola L, Zondi N, Jantjies M (2020) Myths, misconceptions, othering and stigmatizing responses to Covid-19 in South Africa: a rapid qualitative assessment. PLoS One 15:e0244420. https://doi.org/10.1371/journal.pone.0244420

Secosan I, Virga D, Crainiceanu ZP, Bratu LM, Bratu T (2020) Infodemia: another enemy for Romanian frontline healthcare workers to fight during the COVID-19 outbreak. Medicina 56:679. https://doi.org/10.3390/medicina56120679

Sun Z, Cheng X, Zhang R, Yang B (2020) Factors influencing rumour respreading in a public health crisis by the middle-aged and elderly populations. Int J Env Res Public Health 17:6542. https://doi.org/10. 3390/ijerph17186542
Talwar S, Dhir A, Singh D, Virk GS, Salo J (2020) Sharing of fake news on social media: application of the honeycomb framework and the third-person effect hypothesis. J Retail Consum Serv 57:102197. https://doi.org/10.1016/j.jretconser.2020.102197

Tangcharoensathien V, Calleja N, Nguyen T et al (2020) Framework for managing the COVID-19 infodemic: methods and results of an online, crowdsourced WHO technical consultation. J Med Inter Res 22:e19659. https://doi.org/10.2196/19659

Tentolouris A, Ntanasis-Stathopoulos I, Vlachakis PK, Tsilimigras DI, Gavriatopoulou M, Dimopoulos MA (2021) COVID-19: time to flatten the infodemic curve. Clin Exp Med:1-5. https://doi.org/10. 1007/s10238-020-00680-x

Van Der Linden S, Roozenbeek J, Compton J (2020) Inoculating against fake news about COVID-19. Front Psychol 11:2928. https://doi.org/ 10.3389/fpsyg.2020.566790

Vasconcelos-Silva PR, Castiel LD (2020) COVID-19, las fake news y el sueño de la razón comunicativa generando monstruos: el relato de los riesgos y los riesgos de los relatos. Cad Saúde Pública 36: e00101920. https://doi.org/10.1590/0102-311X00101920

Wang C, Pan R, Wan X et al (2020) Immediate psychological responses and associated factors during the initial stage of the 2019 coronavirus disease (COVID-19) epidemic among the general population in China. Int J Env Res Public Health 17:1729. https://doi.org/10.3390/ ijerph17051729

World Health Organization (2020) Novel Coronavirus ( 2019-nCoV): situation report, 3. 2020. World Health Organization, Geneva. https://apps.who.int/iris/handle/10665/330762. February 20, 2021, date of last access

Publisher's note Springer Nature remains neutral with regard to jurisdictional claims in published maps and institutional affiliations. 